\title{
Art \& Space: Eva Petrič's Art Project for Space and in Space
}

\author{
E. Petrič ${ }^{1, *}$, I. L. Schlacht ${ }^{2,3}$, B. Foing ${ }^{3}$ \\ ${ }^{1}$ MFA in New Media, Slovenia \\ ${ }^{2}$ Department of Design, Polytechnic University of Milan, Italy \\ ${ }^{3}$ ESA ESTEC \& ILEWG, The Netherlands
}

Copyright $\bigcirc 2016$ by authors, all rights reserved. Authors agree that this article remains permanently open access under the terms of the Creative Commons Attribution License 4.0 International License

\begin{abstract}
Space can inspire art, and art can inspire space missions. Many artists are inspired by space as a topic to create art, but what would happen if we involved these artists to be part of a space mission? To investigate the potential of involving artists with scientists to perform a space mission, a mission simulation was performed at ESTEC technical centre of the European Space Agency in the ExoLab module on 29 April 2015 as part of a program of the International Lunar Exploration Working Group (ILEWG) [1, 2, 3]. The artist Eva Petrič was invited to take part in the mission simulation in the position of the crew's Health and Safety officer. During the simulation, Eva experienced a strong feeling of isolation. The simulation inspired the artist to propose two art projects aimed at offering emotional support to a potential space crew: the Earthling's mark, a series of tattoos, and DBE $\mathrm{xx} x y$, a unisex fragrance o keep the astronauts in tune with the Earthling in them. The projects were accepted for the poster presentation at the EPSC 2015 conference, which also involved artists for the first time. This paper presents the work of Eva Petrič as a form of communication inspired by space and as a form of communication created in space. In conclusion, art is considered a form of communication that can be related to the artist's perception of personal emotion. Performing art related to space and in space could inspire new forms of communication and lead to socio-cultural evolution.
\end{abstract}

Keywords Space Art, Human Space Mission, Emotion Communication, Cultural Application of Space, Psychological Support

\section{Introduction: Art in Space}

Space must be a place for both scientific and cultural applications. "Art in Space will give a new dimension to the artistic production expanding human culture" (B. Foing in [4]). The use of space as a medium could generate new ideas and applications for both the space industry and the arts. Artists specializing in art \& science can translate their experience into visions that could enhance the quality of life with future forms of art [5]. These artists propose developing new mediums and new ways to approach space missions. This is a form of collaboration in "which scientific concepts are seen as a kind of 'content', and where the artist translates these concepts into images, sounds or other experiences", triggering radically new kinds of artistic development [6].

\section{Mission Simulation}

Space is the most extreme environment that a human could approach. This environment affects the human body and the individual's personal perception with a metamorphosis created by factors such as isolation, radiation, and differences in gravity. This perception alteration could be viewed as a potential for artists to acquire and communicate new emotions. To explore this potential during the ILEWG mission simulation at ESA on 29 April 2015. the crew was composed of scientists as well as artists (e.g., Eva Petrič) [7]. Eva was able to get faster and closer to emotions and to communicate this feeling with respect to the other crew members.

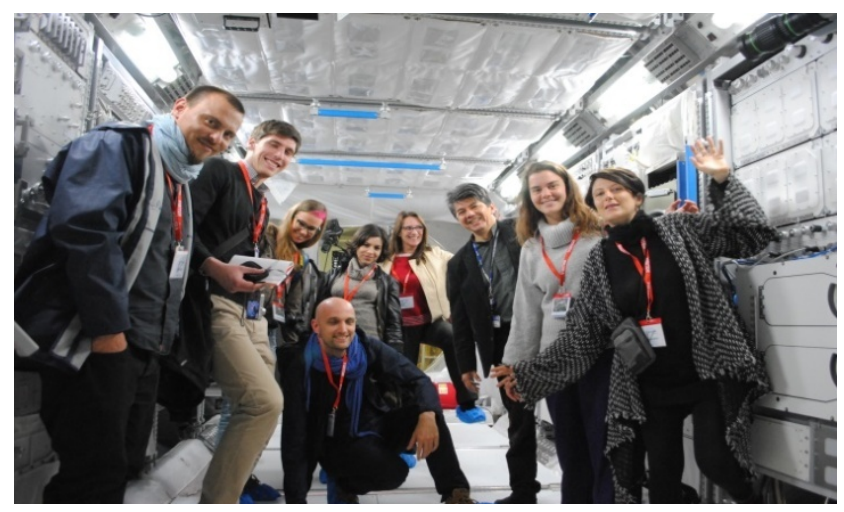

Image 1: Eva ( $4^{\text {th }}$ standing person from the left) and the crew inside Columbus module at the European Space Agency in ESTEC, Holland (2015).

\subsection{Crew Structure \& Task}

The crew (Image 1) had a classical task and hierarchy 
structure, but with members from different humanities \& scientific fields, divided between:

- $\quad$ Remote support: Campaign director (Bernard Foing - science, technology \& logistics), Commander (Irene Lia Schlacht - design \& engineering), Mission support (Jolanda W. Preusterink - operations and education)

- ExoLab: Executive Officer (Miha Tursic - art); Crew Engineer (Guillaume Desmet - engineering architecture); Health \& Safety Officer (Eva Petrič art \& psychology)

- $\quad$ ExoHab: Crew biologist (Spela Petric - bioart)

- ATV observatory: Crew astronomy specialists (Ludwig Pasenau - exoclimatic art); Crew scientist (Natali Blugerman - art \& science)

During the simulation, the crew in EVA performed research on different life forms, while the crew astronomer and the biologist worked in their field of research and also got inspired regarding cultural application. During the EVA, a communication breakdown was planned and two astronauts in EVA performed a safety emergency procedure while the crew biologist and the crew health \& safety officer were left alone, each in one of the modules, trying to reestablish communication. The crew members left alone experienced psychological reactions related to the feeling of isolation. Here, we summarize those results that are relevant to artistic inspiration derived from the simulation.

The simulation inspired the members on the cultural and artistic level.

- Executive Officer Miha Tursic: performed EVA search for life forms; was inspired by questions of developing new life or life-like forms to inhabit the Moon or other planets.

- Crew scientists Natali Blugerman: performed EVA and planet observation; was inspired for her project on an ice observatory as a link between humans and space with elementary elements such as ice and fire developed with an ice lens.

- Crew astronomy specialists Ludwig Pasenau: performed telescopic solar observation to prevent the crew from being exposed to radiation; was inspired by a video shooting of the sun and the atmospheric activity to develop a series of space weather videos. These works could nurture an exoclimatic art project for future astronauts engaged in a long-term mission.

- Crew biologist Spela Petric: provided communication support for the EVA team; was inspired for a new artistic concept on the differences in growing biological life on different planets of our solar system.

- Health \& Safety Officer Eva Petrič: was isolated in the ExoLab module; provided access to her body perception and insights; was inspired to write a text about her sensory perception.

\subsection{Eva Petrič's Projects in Space}

In particular during the simulation, Eva Petric inside the module tried to imagine being in a real confined and isolated place. This gave her a strong perception of her body and emotions, which she reported in a short text composition reported below.

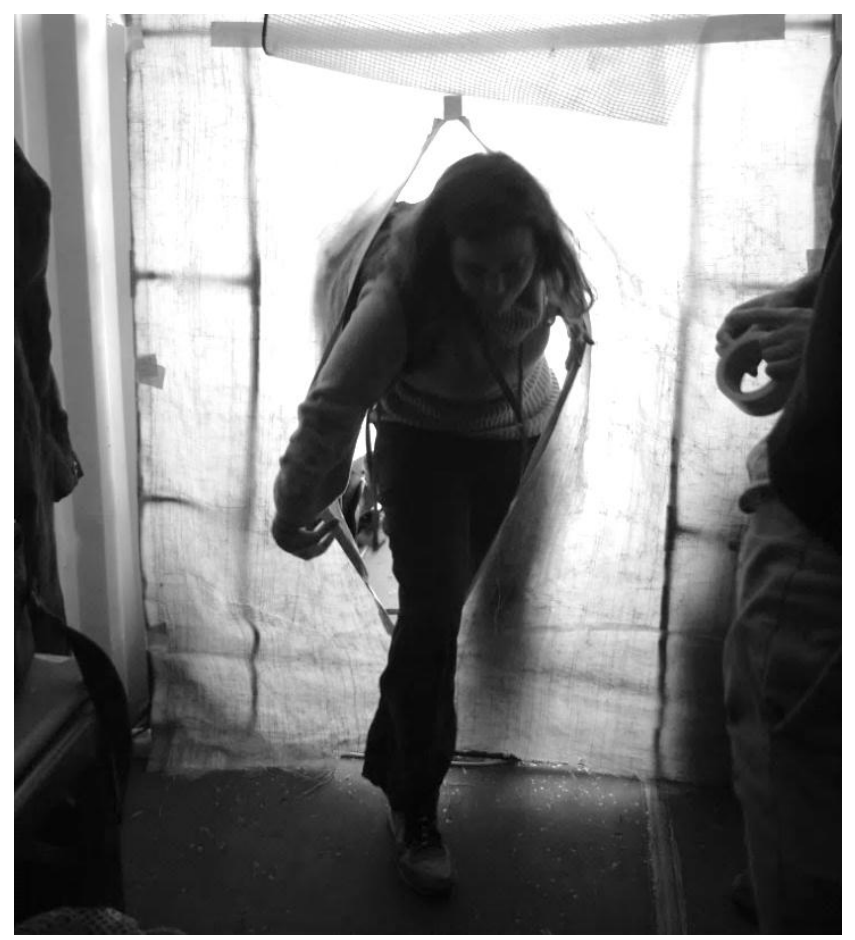

Image 2: Entrance of ExoLab at the European Space Agency in ESTEC, Holland (C) Schlacht 2015).

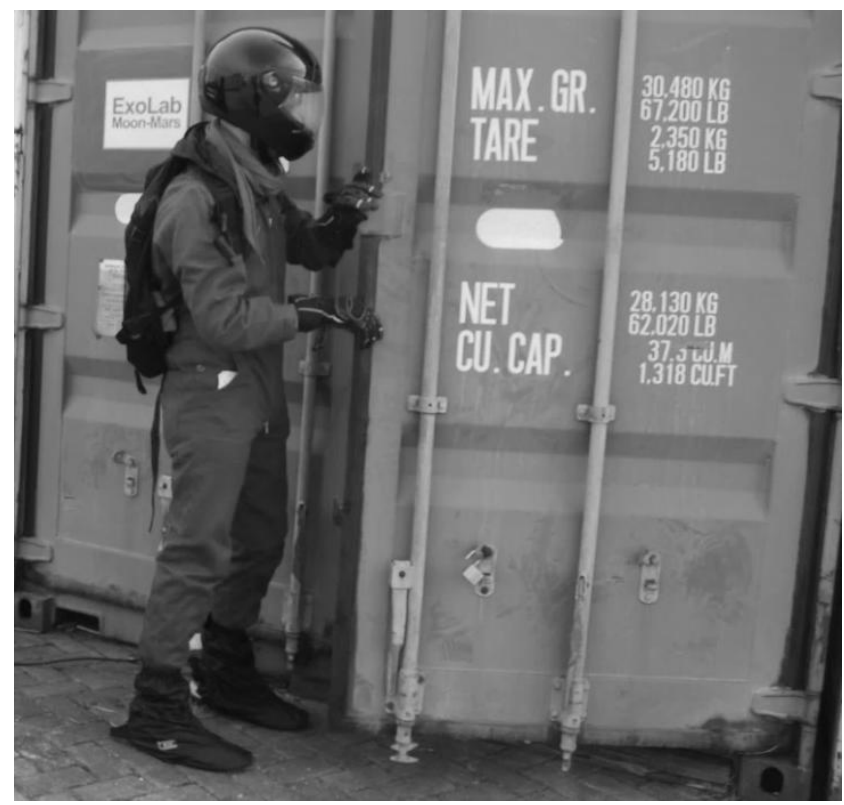

Image 3: Air lock passage to enter inside ExoLab at the European Space Agency in ESTEC, Holland (C) Schlacht 2015). 


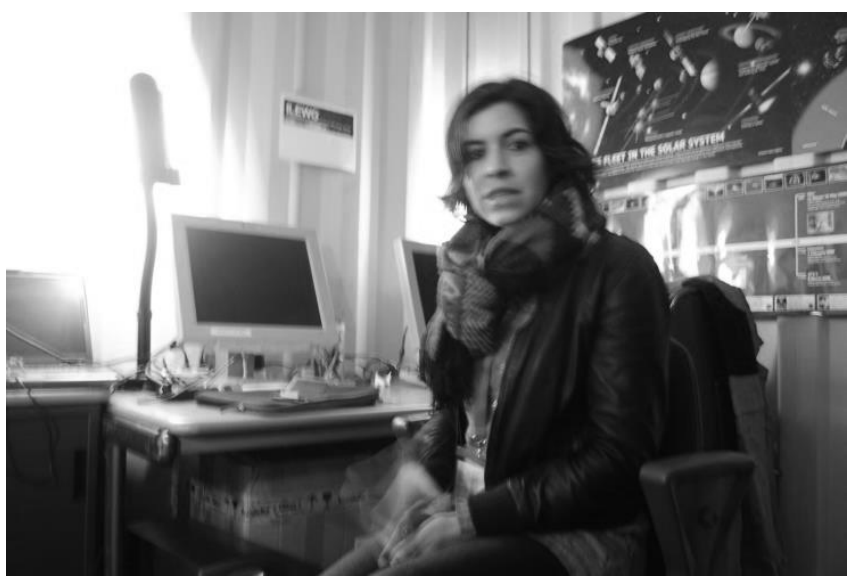

Image 4: Eva in the position of Health \& Safety Officer during the mission simulation inside ExoLab at the European Space Agency in ESTEC, Holland ( (C) Schlacht 2015).

\section{EXPERIENCE OF ISOLATION by EVA Petrič} 29 May 2015, ExoLab, ESA ESTEC, The Netherlands

"After the two astronauts left I found myself listening carefully to try to hear them, and because of this I began to become aware of all the sounds around me much more intensely. While I heard them I was still calm, but after a while I could not hear them anymore and I began to become a bit worried...I waited and waited with a sense of hope and belief that I will hear them again soon and that this will mean that they are returning, but this did not happen. So I began to panic. I began to imagine how something had happened to them and they will not come back and that I was now left abandoned on the Moon. I became scared. I began to check all the equipment, but none of it was working. This made me really scared and I began to feel a feeling of extreme isolation. I felt also physically very cold... I sat back and tried to calm myself by breathing deeply. Images of earth, memories, my family, friends began to flood my mind and this helped to distract me from my fear and feeling of isolation - it helped...then again suddenly a feeling of extreme panic set in and loss of hope and thought of what to do, will I die?! I tried again to calm myself and create poems in my head-melodies. The latter all calmed me down and gave me a good feeling... and suddenly I heard again the voices of the two astronauts and I was filled with joy! This whole experience seemed to me to last for $20 \mathrm{~min}$, but in reality it lasted more than an hour! Time seemed to me to pass by much more quickly to me than it did in reality..."
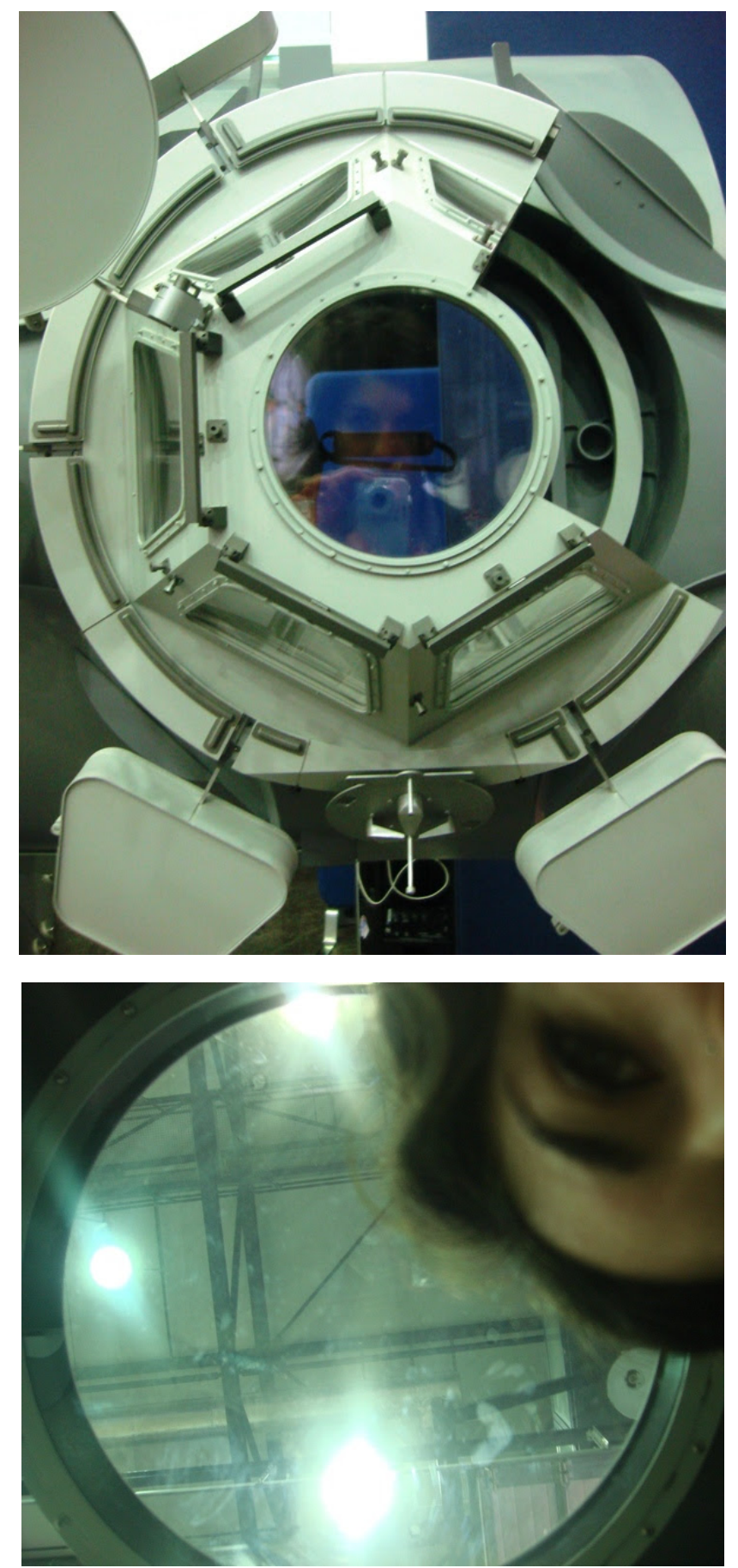

Image 5-6. Eva in the cupola of Columbus, the connecting point with Earth, at ESA/ESTEC in May 2015. (C) Eva Petrič 


\section{Eva Petrič's Projects for Space}

In this section, the webbing art projects [8] stemming from the experience in the space mission simulation at ESA/ESTEC in May 2015 are presented personally by Eva Petrič.

\subsection{Project 1: Earthling's Mark - E mark}

Earthling's mark - E mark, a series of tattoos in the form of a human shadow, translated into the pattern of Idrija1 lace, denoting the unique features of human beings as well as of human society, which is a result of the interconnectedness among human beings, illustrated with web-like lace patterns. The tattoo, applied to the astronauts' wrists, would have a double function: a function of changing the astronaut as a carrier of the tattoo into living art; and a function of providing the astronaut with an emotional charge provided by the artwork. Particularly the form and shape of the Earthling's mark - E mark on the astronaut's wrist would serve as a source of association when the astronaut would look at it, reminding him/her with the loops of the lace pattern of his/her connection to other people, other generations, and to Earth. On the other hand, the tattoo shows through its lace pattern that Earth is part of a huge interplanetary and interstellar web.

The proposed Earthling's mark - E mark stems from my project Gr@y Matter - language of shadows, in which I explored the communication abilities of shadows, expressed as emotions. In the periodic table borrowed from natural sciences, I replaced chemical elements with emotions visualized with images of shadows. These to me denote the DNA of our emotional existence. Parallel to our material existence, presented through chemical elements and molecules, emotions determine our immaterial existence. I decided to rely on emotions and shadows to make Earthling's mark - E mark because both emotions and shadows are equal to all human beings, regardless of the cultural, social, linguistic, or any other differences. Shadows, when looked at, usually produce an association that is connected to emotions.

Shadow emotions, translated into curves and loops of Idrija lace, show not only the zigzag twists and turns of life, but also the interweaving that connects us, similarly to Idrija lace, into unconscious patterns. We are like threads, caught into loops of emotions in patterns of past and future generations.

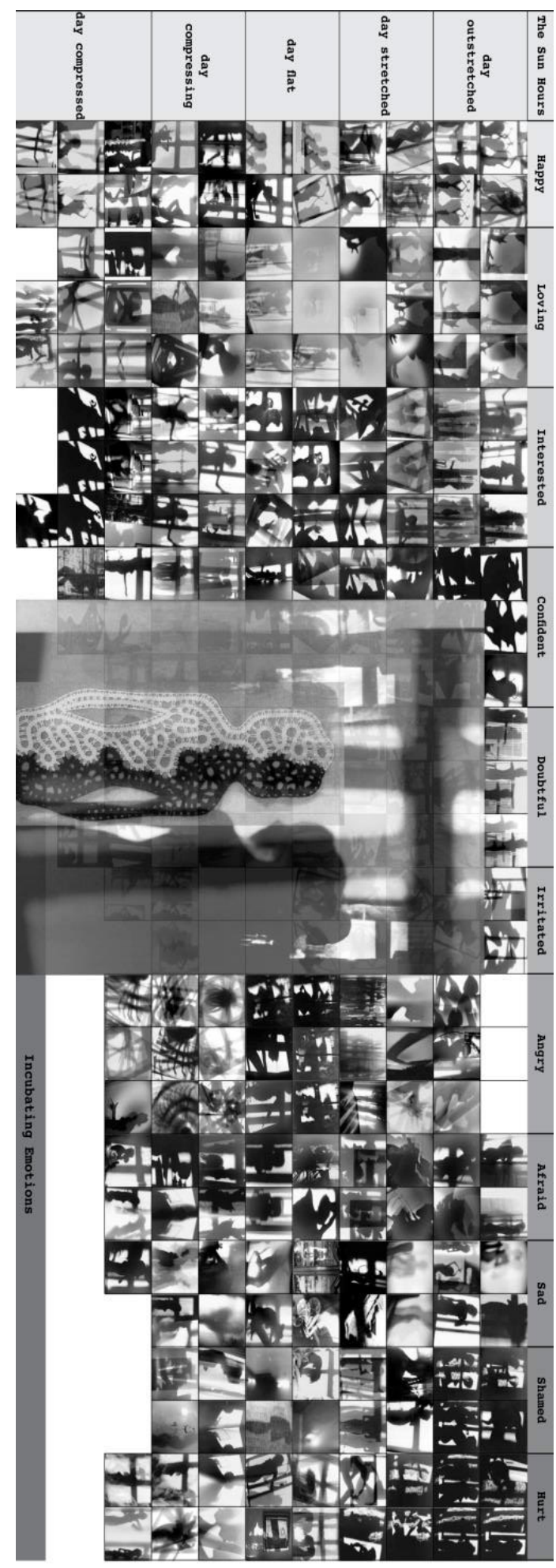

Image 7: Earthling's mark - E mark @ Eva Petrič

\footnotetext{
${ }^{1}$ Idrija is a place in Slovenia where a unique pattern of making lace was developed in the 19th century.
} 


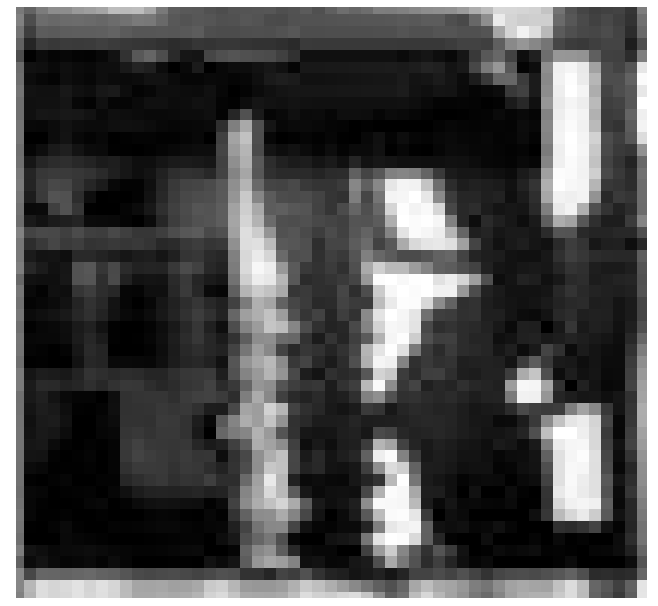

Image 8: Detail of Earthling's mark - column "Happy". E mark (C) Eva Petrič

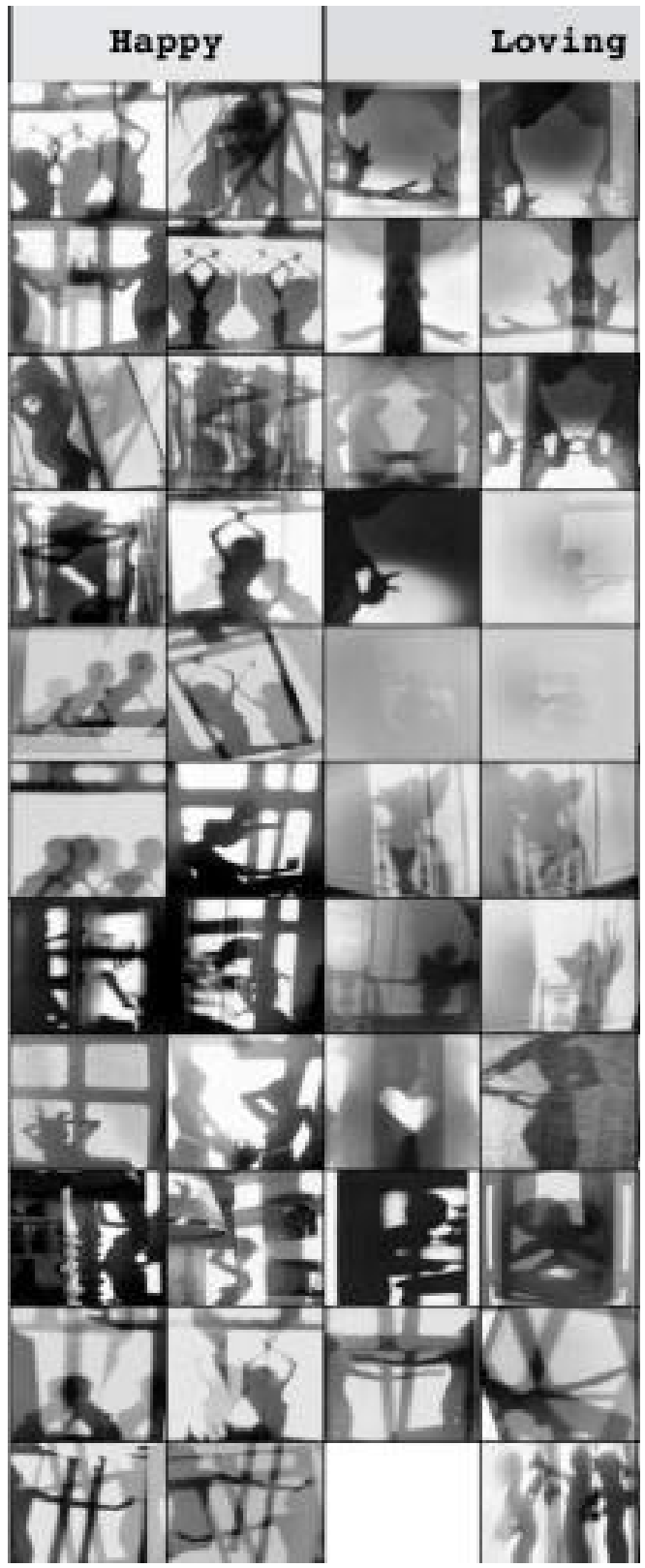

Image 9: Detail of Earthling's mark - E mark @ Eva Petrič

\subsection{Project 2: DBE xx xy}

DBE xx xy (unisex fragrance) - to keep the astronauts in tune with the Earthling in them. I propose equipping astronauts with fragrance tissues to keep them »in tune « with the Earthling in them. Function: to call on the memories of life on Earth. Scientists have discovered the connection between smell and memories - certain smells have the ability to evoke certain memories. Smells can evoke even the most distant memories, unconscious memories, transgenerational memories, and even primordial memories. Instead of EDT (Eau de Toilette), I invented a new term, DBE, Data Bank of Emotions, denoting that this is not just a fragrance but rather an emotion tuner, tuning one into one's optimal feelings. I propose printing the Earthling's mark - E mark (described in project 1) on these fragrance tissues. The printed figure, which is a shadow silhouette translated into a lace pattern, denotes the human body. The loops, twists, and turns of the lace demonstrate the interweaving and interconnecting process in a human body as well as society, the form thus preserving and accentuating our human origin. The fragrance used would be pure double spicy, formulated according to my instructions.
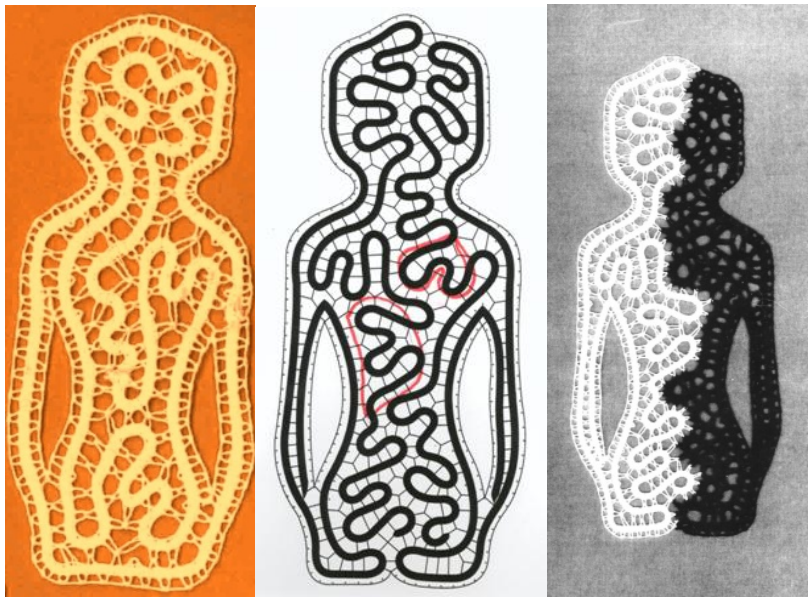

Image 10: Earthling's mark - E mark (c) Eva Petrič

\section{Post-Mars Mission Simulation Artistic Ideas and Production}

The experience of isolation during the Mars Mission Simulation has a profound influence on my art. When I retrospect on my art production and my art ideas originating during the past year after completing the above Mars Mission Simulation, I am noticing a significant move in the direction of exploring the phenomenon of webbing, tying every single individual part of whatever exists in this Universe into a broader webbing constellation. Wanting or not, being aware of or not, everything in this Universe is interconnected - meaning, that the extreme isolation I felt during the Mars Mission Simulation, in this Universe does not exist. Since the experience of the extreme feeling of 
isolation I tend now to see - and reflect this in my art since then - the phenomenon of webs on all levels: from nano to expo, from a cellular level to galactic levels. I expressed this concept of this ultimate connection and communication and interconnectedness through the series of my web-like lace assemblages, made of inherited, given, found and at the flea markets around the world bought hand-made lace works. These works in various lace patterns with their knots and ties illustrate to me that everything is interconnected regardless of our awareness or non-awareness of this. One thing does not exist without being connected to other parts - hence the feeling of extreme isolation does not illustrate the reality. Precisely through my art made after the space mission simulation I have realized that "extreme isolation does not exist - the feeling of it is indeed only the result of a psychological construct". My art reflected this realization even before I became aware of it.

Realizing this in the course of writing this paper - not indeed as a scientific expertise but as a kind of self-analysis of how the space mission simulation influenced my personality and thus my artistic perspective $-\mathrm{I}$ can now state firmly that "space mission experience" has the power to change one's attitude. I see this clearly on the basis of the kind of art that I produced since the Mars Mission Simulation experience. Maybe, as an artist I am more sensitive and more perceptive than majority of people are. However, this only shows that space plays role in art and vice versa: art can help adapt to the extremes of space affecting the psyche of people experiencing it.

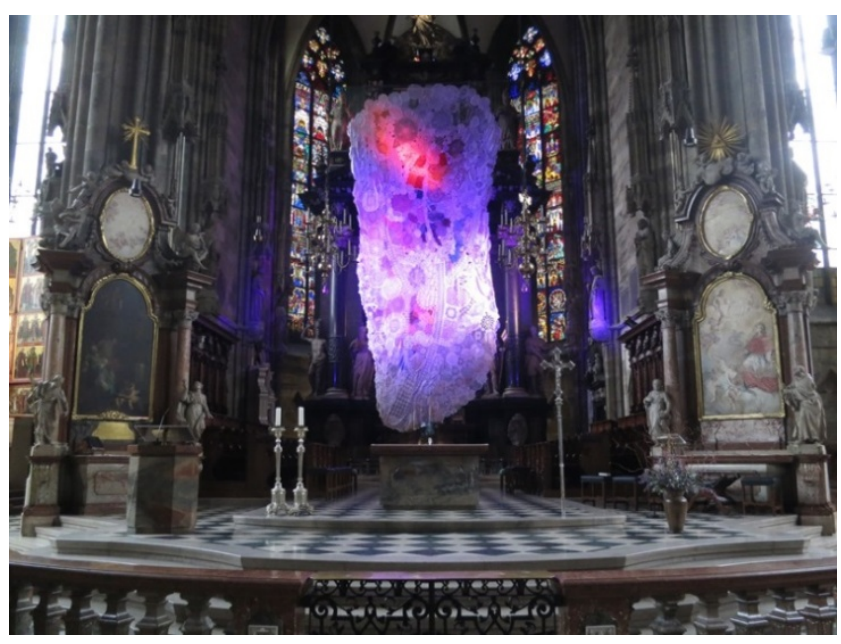

Image 11: Collective Heart, site specific installation at the St. Stephan's Cathedral, Vienna, Austria, Feb.8 - March 282016 C Eva Petrič

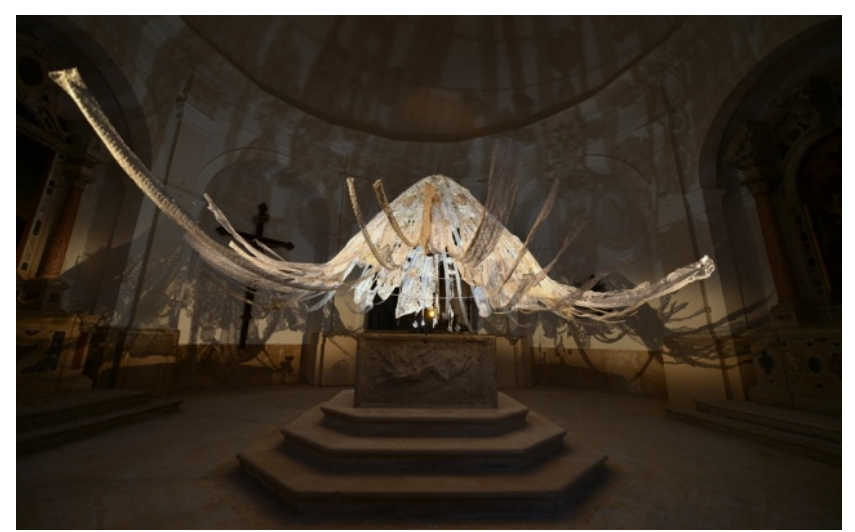

Image 12: Angel's Shadow, site specific art installation, Ancient Baptistery, Piran, Slovenia, August 2015 (C) Eva Petrič

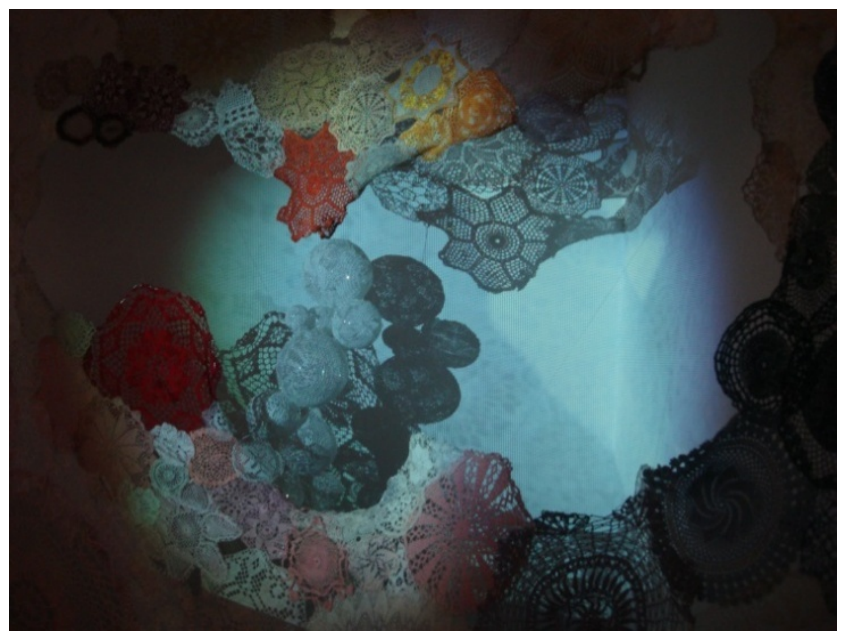

Image 13: Minding Collagen, Kro Art Contemporary, Vienna, Austria, Sept. - Decmber 2015@ Eva Petrič

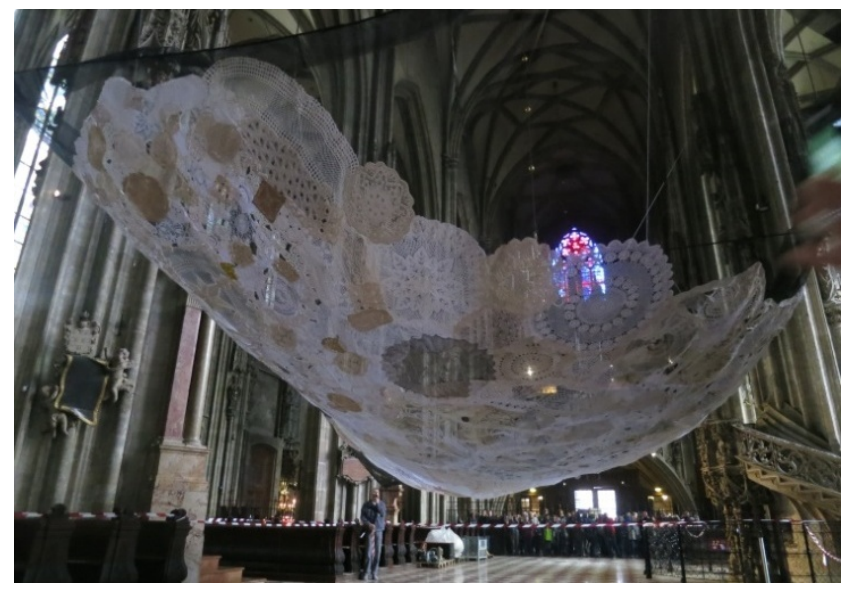

Image 14: Love-belief-hope, site specific art installation, St. Stephan's Cathedral, Vienna, Austria, May5 - June 15, 2016@ Eva Petrič 


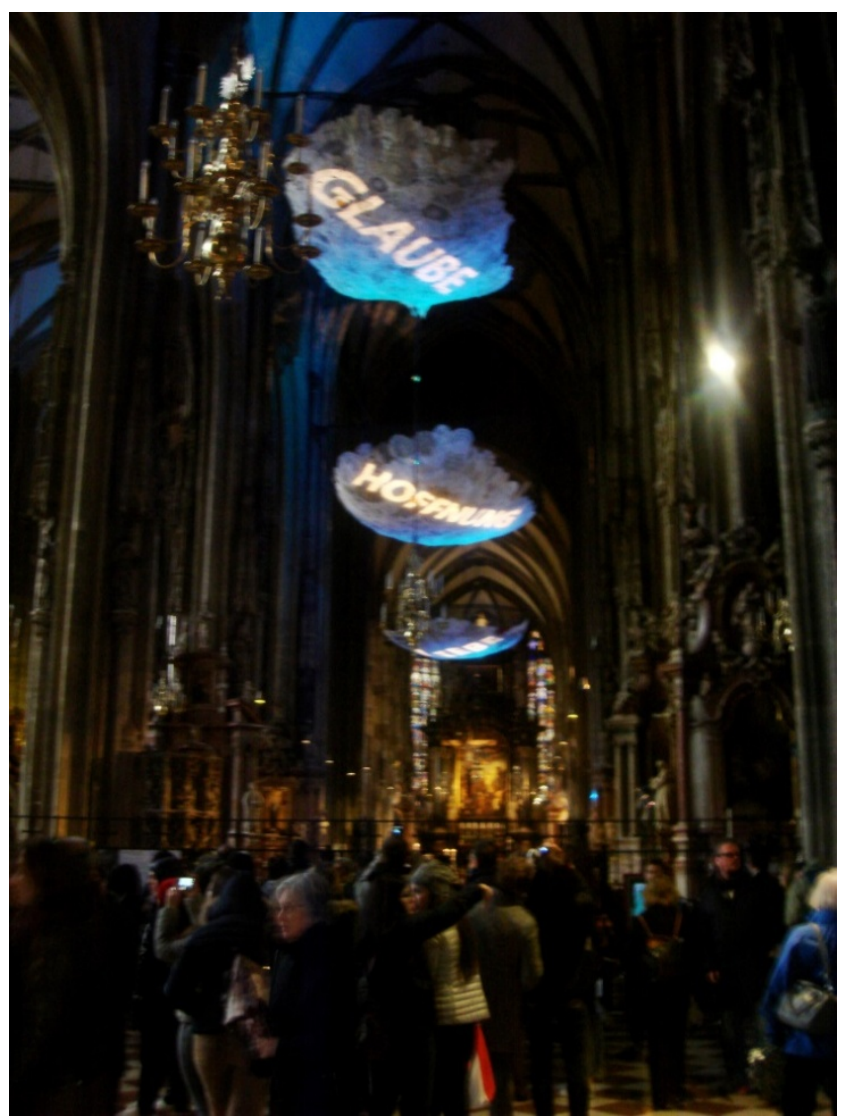

Image 15: Love-belief-hope, site specific art installation, St. Stephan's Cathedral, Vienna, Austria, May5 - June 15, 2016@ Eva Petrič

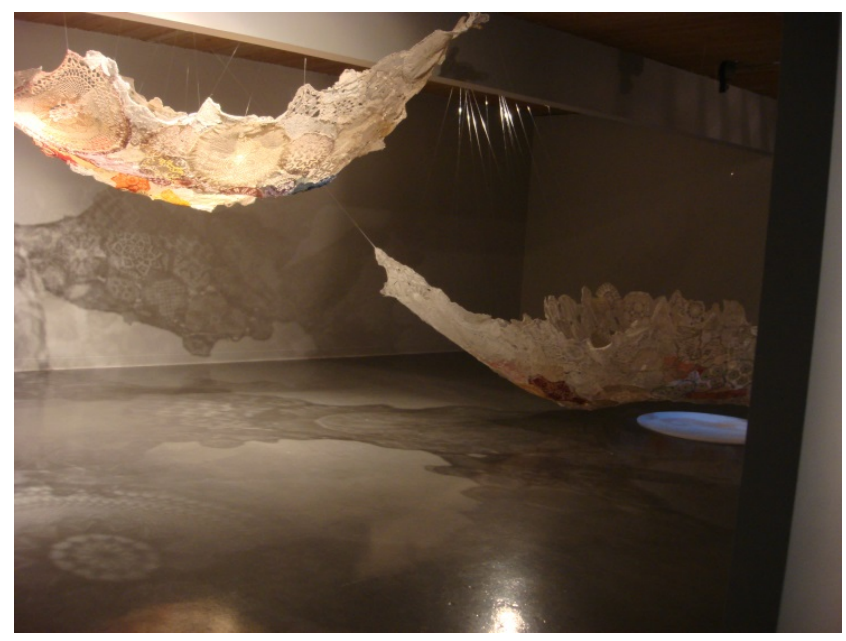

Image 16: SubDUCTion Zone, Hunt Gallery, St.Louis, USA, Febr. 19March 20, 2016, (C) Eva Petrič

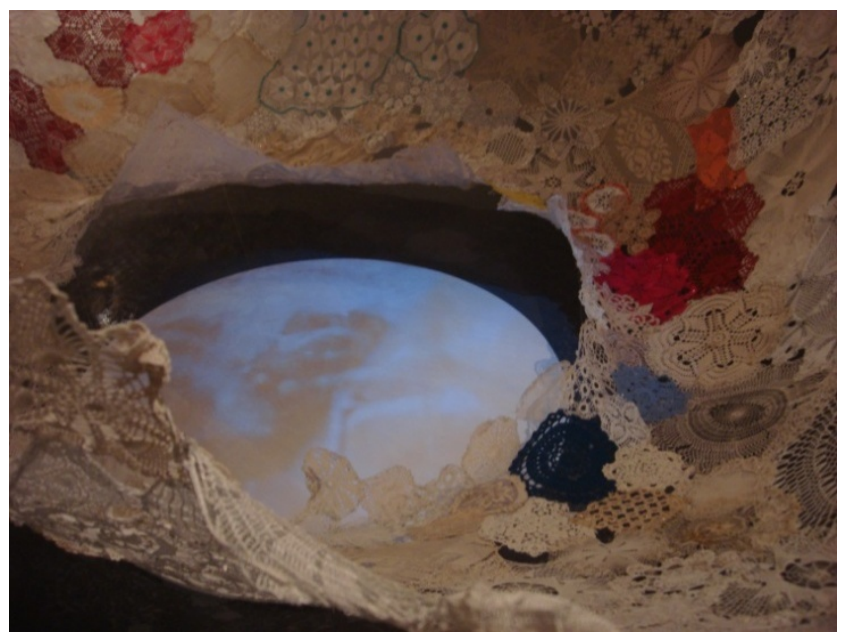

Image 17: SubDUCTion Zone, Hunt Gallery, St.Louis, USA, Febr. 19 March 20, 2016,@ Eva Petrič

\section{Conclusions}

"Art in Space will give a new dimension to the artistic production expanding human culture" [4]. The correlation of artistic activity through cooperation in space could increase the potential of communication in space exploration.

The concluding message of the artist Eva Petrič is: "Water (brine) flows on Mars, but isolation persists...Wishing your imagination to fly high and far inspired by the discovery of water on our closest planetary neighbor, Mars."

\section{Acknowledgements}

MFA in new media, Slovenia / Austria / U.S.A., International Lunar Exploration Working Group (ILEWG), ESA ESTEC, Politecnico di Milano.

\section{REFERENCES}

[1] Schlacht I.L. (2012). SPACE HABITABILITY: Integrating Human Factors into the Design Process. TU Berlin, Germany.

[2] Schlacht, I.L. Foing, B., Ceppi, G. (2015). Exohab1 development: spin-in/out from space habitat to disaster management facility. 66th IAC 2015 
[3] Schlacht, I.L. (Ed.). (2011). Chapter: Space Extreme Design. In Personal and Ubiquitous Computing. Volume 15 Number 5 pp. 487-526.

[4] Schlacht, I.L., \& Ono, A. (2009). Creative Process to Improve Astronaut Reliability. IAC-09.B3.2.4. Proceeding of 60th IAC, 12-16.10.2009, Daejeon, Korea. page.4 www.iafastro.net/download/congress/IAC-09/DVD/full/ (insert on the search: Schlacht)

[5] KABK (2015). ArtScience. Royal Academy of Art. KABK Den Haag. www.kabk.nl/pagewideNL.php?id=0002

[6] KABK (2015). Art and Science. Royal Academy of Art.
KABK Den Haag. www.kabk.nl/pagewideNL.php?id=0007

[7] Schlacht, I.L.; Foing, B., Preusterink, J.W., Petric, E., Tursic, M., Petric, S., Pasenau, L., Desmet, G., Blugerman, N., Ceppi, G. (2015). ExoLab Space Mission Simulation: Expanding life with art \& science. Abstract and Poster for the European Planetary Science Congress 2015, 27.09 - 02.10 2015. La Cité des Congrès, Nantes, France.

[8] Petric, E., Schlacht, I.L., Foing, B. (2015). Art \& Space: the webbing projects of Eva. Abstract and Poster for the European Planetary Science Congress 2015, 27.09 - 02.10 2015. La Cité des Congrès, Nantes, France. 